\title{
Fluid inclusions in minerals of the deep crust - Investigations with the new high vacuum crushing system at the CSIRO noble gas facility
}

\author{
CORNELIA WILSKE ${ }^{1,2}$, AXEL O. SUCKOW ${ }^{2}$, ALEC \\ DESLANDES $^{2}$, PUNJEHL CRANE ${ }^{2}$, CHRISTOPH GERBER ${ }^{2}$, \\ NIGEL SPOONER ${ }^{1}$ AND DIRK MALLANTS ${ }^{2}$ \\ ${ }^{1}$ The University of Adelaide \\ ${ }^{2}$ CSIRO \\ Presenting Author: cornelia.wilske@adelaide.edu.au
}

Tracing noble gases provides a unique tool to investigate various geological processes from macro to micro scales. In geologic formations with very slow to no advective groundwater flow (e.g., aquitards and shales), noble gases, especially helium, are excellent tracers for quantifying diffusion-dominated transport. In "dry" formations of extremely low porosity and permeability, such as igneous rocks, noble gases within fluid inclusions are studied to assess the chronology of ancient fluid migration in the rock matrix and of mineralisation processes.

The Environmental Tracer Laboratory (ETL) of CSIRO at Waite Campus, South Australia, has developed a new high vacuum crushing system to extract fluid inclusions from minerals to measure their noble gas concentrations and isotopic composition. It operates with one of only a few High-Resolution Noble Gas Mass Spectrometers in Australia (Helix MC Plus). The preparation system allows purifying the noble gas fractions and measuring in fully automated mode rare isotope ratios like ${ }^{136} \mathrm{Xe} /{ }^{132} \mathrm{Xe},{ }^{21} \mathrm{Ne} /{ }^{20} \mathrm{Ne}$ and ${ }^{3} \mathrm{He} /{ }^{4} \mathrm{He}$ in groundwater and pore fluids. In fluid inclusions, these noble gas isotopes are the only means to evaluate how long pore fluids were isolated from the water cycle and to quantify primordial and radiogenic components. We present technical details of the high vacuum crusher and the first experimental outcomes based on deep granite samples. 